\title{
Optimal cutoff points for body mass index, waist circumference and HOMA-IR to identify a cluster of cardiometabolic abnormalities in normal glucose-tolerant Brazilian children and adolescents
}

\author{
Valores de corte ótimos do índice de massa corporal, \\ circunferência abdominal e HOMA-IR para a identificação de \\ um conjunto de anormalidades cardiometabólicas em crianças \\ e adolescentes brasileiros com tolerância normal à glicose
}

\footnotetext{
1 Endocrinology Division and Diabetes Center, Universidade Federal de São Paulo (Unifesp), São Paulo, SP, Brazil

2 Psicobiology Department, Unifesp, São Paulo, SP, Brazil
}

Eloa R. Rocco', Denise Barretto Mory', Carla Sanchez Bergamin', Fernando Valente', Valquíria Lopes Miranda', Bruno Frederico Aguilar Calegare², Regina Quirino Silva', Sérgio Atala Dib'

\section{ABSTRACT}

Objective: The aim of this study was to establish the best cutoff values for waist circumference (WC), body mass index (BMI) and HOMA-IR (HR) to identify a cluster $(\geq 3)$ of cardiovascular risk factors (CVRF) in normal glucose-tolerant (NGT) Brazilian children and adolescents. Subjects and methods: Cross-sectional study of 319 individuals (aged 10 to 19y) from a southern Brazilian city. Gender-specific receiver-operating characteristics (ROC) curves were constructed to assess cutoffs values of BMI $\left(\mathrm{kg} / \mathrm{m}^{2}, \mathrm{WC}(\mathrm{cm})\right.$, and HR. Results: The areas under the ROC curves to detect a cluster of CVRF were $0.92,0.93$ and 0.68 (females), and $0.93,0.93$ and 0.89 (males), for WC, BMI and HR, respectively. The cutoff values were 83.0 and $80.5 \mathrm{~cm}(\mathrm{WC}), 22.7$ and 20.4 $\mathrm{kg} / \mathrm{m} 2$ (BMI), and 1.65 and $1.95(\mathrm{HR})$, for females and males, respectively, to detect the cluster of CVRF. Conclusion: These values of BMI, WC-) and (HR) detected a high proportion of NGTt Brazilian children and adolescents with a cluster of CVRF. Arq Bras Endocrinol Metab. 2011;55(8):638-45

\section{Keywords}

Children; adolescents; cardiovascular risk factor; cluster

\section{RESUMO}

Objetivo: O objetivo deste estudo foi estabelecer os melhores valores de corte para circunferência abdominal (CA), índice de massa corpórea (IMC) e HOMA-IR (HR) para identificação da concomitância de um conjunto de fatores de risco cardiovascular $(\geq 3)$ em crianças e adolescentes brasileiros com tolerância normal à glicose (TNG). Sujeitos e métodos: Estudo transversal realizado em uma cidade do sudeste do Brasil com 319 indivíduos de 10 a 19 anos de idade. Curva ROC para cada gênero foi utilizada para estabelecimento dos valores de IMC $\left(\mathrm{kg} / \mathrm{m}^{2}\right), C A$ (cm) e HRR. Resultados: As áreas sob as curvas ROC para detectar o conjunto de fatores cardiovascular foram 0,92, 0,93 e 0,68 (meninas) e 0,93, 0,93 e 0,89 (meninos) para CA, IMC e HR, respectivamente. Os valores de corte foram 83,0 e $80,5 \mathrm{~cm}$ (CA), 22,7 e 20,4 kg/m² (IMC) e 1,65 e 1,95 (HR), para meninas e meninos, respectivamente, para detecção do grupo de fatores de risco cardiovascular. Conclusão: Esses valores de IMC,CA e HR detectaram uma porcentagem significativa de crianças e adolescentes brasileiros com TNG e elevado risco cardiovascular. Arq Bras Endocrinol Metab. 2011;55(8):638-45

Descritores

Crianças; adolescentes; fator de risco cardiovascular; cluster 


\section{INTRODUCTION}

$\mathrm{T}$ he prevalence of overweight and obesity in children is increasing rapidly, and the ongoing obesity epidemic represents a major public health burden worldwide $(1,2)$. The prevalence of overweight among Brazilian adolescents has risen from $4.0 \%$ to $13.0 \%$ over a 20 -year period (3).

The natural history of insulin resistance (IR) may begin in the intrauterine life and, after birth, it may continue to develop as a result of the interaction between genetic and environmental factors. The combination of IR and subsequent hyperinsulinemia with a number of metabolic and cardiovascular risk factors (CVRF) has become known as metabolic syndrome (Met-S) (4). In a previous report of our group, we found that the prevalence of Met-S was $6 \%$ for the whole sample of adolescents, and $26.1 \%$ in the obese subgroup (5).

It has been shown that visceral adiposity is independently associated with a cluster of CVRF compared to total adiposity (6-8). It is important to investigate when IR starts to be related with cardiometabolic abnormalities among adolescents, and what relationship it might have with waist circumference (WC).

In the last consensus for the study of IR in children (9), it was found that there was no justification for screening children for IR, because there are no clear criteria to define this condition in this age group, and that the two most important biological conditions associated with the IR were ethnicity and puberty.

In this study, we identified the prevalence of a cluster of cardiometabolic abnormalities at different levels of insulin resistance in a group of children and adolescents with normal glucose tolerance. We also established the best cutoff values for the HOMA-IR index, WC and BMI to identify normal glucose-tolerant Brazilian children and adolescents with a cluster of CVRF.

\section{RESEARCH DESIGN AND METHODS}

This is a cross-sectional study of a total of 319 children and adolescents recruited from an elementary school in the metropolitan area of the city of São Paulo, SP, Brazil. The inclusion criteria were that subjects were healthy and between 10 and 19 years old. In addition, none of these subjects should be taking medications that are known to have an impact on insulin sensitivity. This study was approved by the Ethics Committee of the Universidade Federal de São Paulo. Informed consent was obtained from all participants or his/her parents or guardians.

The subjects were assessed at $8 \mathrm{am}$, after a 12 -h overnight fast. A detailed medical history was obtained from all subjects, including information on race, physical activity, and type 2 and gestational diabetes mellitus in first- or second-degree relatives.

Anthropometric measurements were performed, blood pressure was measured and an intravenous antecubital catheter was placed. Blood was drawn for laboratory at fasting for the analyses of fasting plasma glucose (FPG) and serum insulin, and again after 120 min of a glucose load $(1.75 \mathrm{~g} / \mathrm{kg}$, $\max 75 \mathrm{~g})$. A physician performed the examination for Acanthosis nigricans and Tanner staging (10).

Body mass index (BMI, $\left.\mathrm{kg} / \mathrm{m}^{2}\right)$ and BMI percentiles were then calculated using the age and gender-specific percentiles of the Centers for Disease Control (CDC). The participants were grouped as presenting normal weight $\left(\mathrm{BMI}<85^{\text {th }}\right.$ percentile), overweight $\left(85^{\text {th }} \geq \mathrm{BMI}<95^{\text {th }}\right.$ percentile $)$ and obese $\left(\mathrm{BMI} \geq 95^{\text {th }}\right.$ percentile) (11).

WC was measured with a flexible tape, midway between the lowest rib and the superior border of the iliac crest (12). Systolic and diastolic blood pressure was measured in the right arm, in a sitting position, using a calibrated sphygmomanometer with appropriate cuff size, under standard conditions. Children whose systolic or diastolic blood pressure exceeded the $90^{\text {th }}$ percentile for the age and gender were considered hypertensive (13).

Physical activity levels were assessed using the International Physical Activity Questionnaire (IPAQ-8, short version). IPAQ is a questionnaire made available by the WHO for assessing physical activity worldwide and it is currently in use in 12 countries (14). This questionnaire includes questions about the duration and intensity of physical activity during a "usual" week, in occupational, transport, leisure, or sports activities.

The American Diabetes Association criteria (ADA, 2009) were used for glucose tolerance classification (15). The homeostasis model of insulin resistance (HOMA-IR) index and $\beta$-cell function (HOMA-B) were calculated using the HOMA model software (University of Oxford, Oxford, UK) (16).

The HOMA-IR index from a subgroup of 202 subjects of the same age and gender of the studied population with normal BMI and glucose tolerance were categorized in the percentiles 5 to 25,25 to 50,50 to 85 , 85 to 95 and $>95$, and ranged from 0.4 to $0.8,0.81$ to 
$1.2,1.21$ to $2.0,2.1$ to 2.92 and $>2.93$, respectively, as a normal distribution.

Abdominal obesity ( $\geq 90^{\text {th }}$ percentile), hypertension $\left(\geq 90^{\text {th }}\right.$ percentile), increased level of triglycerides $(\geq 10 \mathrm{mg} / \mathrm{dL})$, decreased HDL-cholesterol levels $(\leq 40$ $\mathrm{mg} / \mathrm{dL}$ ), and hyperglycemia ( $\geq 100 \mathrm{mg} / \mathrm{dL}$ ) were used as the cluster of cardiometabolic abnormalities in the present study. The set of three or more of these variable was known as metabolic syndrome, in accordance with NCEPATPIII (National Cholesterol Education Program's Adult Treatment Panel III), modified for the age (17).

We used ROC curves to choose the cutoff points for BMI, HOMA-IR and WC to identify the cluster of cardiometabolic abnormalities in the same individual. We preferred to choose higher sensitivities to identify children with CVRF.

\section{BIOCHEMICAL ANALYSIS}

Plasma glucose levels were determined by a glucose hexokinase II (Bayer ADVIA 1650 analyzer), and cholesterol levels by an enzymatic method (Bayer ADVIA 1650 analyzer). The TG method was based on the Fossati three-step enzymatic reaction with a Trinder endpoint (Bayer ADVIA 1650 analyzer).

Plasma insulin was measured by Auto DELFIA time-resolved fluoroimmunoassay (Wallac Oy, Turku, Finland). The intra-assay variations $(\% \mathrm{CV})$ were 2.4 and $1.7 \%$ for 5.65 and $30.2 \mu \mathrm{U} / \mathrm{mL}$, respectively. The inter-assay variations $(\% \mathrm{CV})$ were 2.3 and $3.5 \%$ for the same insulin values shown above, respectively. Homocysteine (Hcy) was measured by means of HPLC for plasma total homocysteine and cysteine.

HbAlC was measured by HPLC (normal range $3.5 \%-6.0 \%)$.

\section{STATISTICAL ANALYSIS}

All values were expressed as means \pm SD. Boys and girls were compared according to demographic, clinical and laboratory characteristics using qui-square test or Student's t test. Mean HOMA-IR, BMI and WC were compared using the Student's t test or the MannWhitney test. The ROC curve was used to define the cutoff values of HOMA-IR, BMI and WC to identify the cluster of cardiometabolic abnormalities, and $\mathrm{p}$-values lower than 0.05 were considered statistically significant.

\section{RESULTS}

The characteristics of the 319 children and adolescents, physical findings, and laboratory results are found in table 1 .

Table 1. Descriptive characteristics of children and adolescents studied

\begin{tabular}{|c|c|c|c|}
\hline n & $\begin{array}{c}\text { Girls } \\
179(56.1 \%)\end{array}$ & $\begin{array}{c}\text { Boys } \\
140(43.9 \%)\end{array}$ & $p$ value \\
\hline AGE (years) & $13.1 \pm 2.5$ & $13.2 \pm 2.4$ & ns \\
\hline \multicolumn{4}{|l|}{ RACE } \\
\hline White & 75 (41.9\%) & $52(37.1 \%)$ & ns \\
\hline Non-white & $104(58.1 \%)$ & $88(62.9 \%)$ & ns \\
\hline $\begin{array}{l}\text { Family history of type } 2 \\
\text { diabetes mellitus }\end{array}$ & $104(58.1 \%)$ & $101(72.1 \%)$ & 0.013 \\
\hline BMI $\left(\mathrm{kg} / \mathrm{m}^{2}\right)$ & $22.5 \pm 5.9$ & $21.3 \pm 4.7$ & ns \\
\hline TANNER & $4.1 \pm 1.2$ & $3.2 \pm 1.5$ & $<0.001$ \\
\hline $\mathrm{SBP}(\mathrm{mmHg})$ & $109.0 \pm 14.7$ & $108.7 \pm 16.1$ & ns \\
\hline $\mathrm{DBP}(\mathrm{mmHg})$ & $66.8 \pm 12.4$ & $65.8 \pm 13.2$ & ns \\
\hline WC (cm) & $76.8 \pm 16.7$ & $74.8 \pm 14.6$ & ns \\
\hline Physical activity & $0.8 \pm 0.8$ & $1.6 \pm 1.2$ & $<0.001$ \\
\hline Birth weight (g) & $3117.7 \pm 635.0$ & $3323.6 \pm 739.3$ & 0.013 \\
\hline Acanthosis nigricans & $40(22.3 \%)$ & $17(12.1 \%)$ & 0.027 \\
\hline $\mathrm{TC}(\mathrm{mg} / \mathrm{dL})$ & $162.5 \pm 33.7$ & $156.5 \pm 30.7$ & ns \\
\hline $\mathrm{HDL}(\mathrm{mg} / \mathrm{dL})$ & $49.7 \pm 11.7$ & $48.5 \pm 10.8$ & ns \\
\hline LDL-C (mg/dL) & $92.9 \pm 25.9$ & $91.3 \pm 25.0$ & ns \\
\hline $\mathrm{TG}(\mathrm{mg} / \mathrm{dL})$ & $98.0 \pm 60.3$ & $80.6 \pm 30.3$ & 0.018 \\
\hline HbA1c (\%) & $5.2 \pm 0.3$ & $5.4 \pm 0.4$ & $<0.001$ \\
\hline $\mathrm{FPG}(\mathrm{mg} / \mathrm{dL})$ & $81.3 \pm 11.0$ & $82.8 \pm 9.4$ & 0.054 \\
\hline $2 \mathrm{hPG}(\mathrm{mg} / \mathrm{dL})$ & $86.1 \pm 18.2$ & $85.4 \pm 18.1$ & ns \\
\hline $\mathrm{FSI}(\mu \mathrm{U} / \mathrm{mL})$ & $14.0 \pm 14.0$ & $9.3 \pm 7.4$ & $<0.001$ \\
\hline HOMA-B (\%) & $178.0 \pm 72.8$ & $139.2 \pm 75.6$ & $<0.001$ \\
\hline HOMA-IR & $1.7 \pm 0.9$ & $1.3 \pm 1.0$ & $<0.001$ \\
\hline $\mathrm{HCY}$ & $8.8 \pm 2.1$ & $9.6 \pm 2.0$ & 0.010 \\
\hline
\end{tabular}

There were no differences in mean age, race, BMI, WC, blood pressure, cholesterol levels, or 2-hour plasma glucose among the gender groups. Girls tended to be at a higher Tanner stage $(4.1 \pm 1.2$ vs. $3.2 \pm 1.5$; $\mathrm{p}<0.001)$ and to have lower physical activity $(0.8 \pm 0.8$ vs. $1.6 \pm 1.2 ; \mathrm{p}<0.001)$ than boys. Triglycerides were higher among the girls $(98.0 \pm 60.3 \mathrm{mg} / \mathrm{dL} v s .80 .6 \pm$ $30.3 \mathrm{mg} / \mathrm{dL} ; \mathrm{p}=0.018$ ).

Seven of the 319 subjects presented impaired fasting plasma glucose (IFG) $(\geq 100 \mathrm{mg} / \mathrm{dL}$ and $<126 \mathrm{mg} /$ $\mathrm{dL}$ ), but none had impaired glucose tolerance (IGT) ( 2 h-plasma glucose $\geq 140 \mathrm{mg} / \mathrm{dL}$ and $<200 \mathrm{mg} / \mathrm{dL}$ ) in the first analysis. None of them presented confirmed IFG after another oral glucose tolerance test (OGTT). $\mathrm{HbAlc}$ was higher in boys than in girls $(5.4 \pm 0.4 v s$. $5.2 \pm 0.3 \% ; \mathrm{p}<0.001)$. 
Girls had higher fasting serum insulin $(14.0 \pm 14.0$ vs. $9.3 \pm 7.4 \mu \mathrm{U} / \mathrm{mL} ; \mathrm{p}<0.001)$, HOMA-IR $(1.7 \pm$ 0.9 vs. $1.3 \pm 1.0 ; \mathrm{p}<0.001$ ), and higher HOMA-B $(178.0 \pm 72.8$ vs. $139.2 \pm 75.6 ; \mathrm{p}<0.001)$ than boys. On the other hand, boys had higher Hcy than girls (8.8 \pm 2.1 vs. $9.6 \pm 2.0 \mathrm{mmol} / \mathrm{L} ; \mathrm{p}=0.010$ ).

Further, 297 individuals with complete data required for Met-S definition, were classified according to HOMA-IR percentiles, as shown in table 2. These groups did not differ significantly in relation to age, Tanner stage, DBP, birth weight, HbAlc, Hcy, or family history of type 2 diabetes mellitus.

The group with lower insulin resistance $\left(\mathrm{G}_{\mathrm{p} 5-25}\right)$ presented greater prevalence of males, higher levels of physical activity $(1.5 \pm 1.3$ vs. $0.9 \pm 0.9 ; \mathrm{p}=0.047)$, higher $\operatorname{HDL}(53.4 \pm 12.8 v s .46 .8 \pm 15.6 \mathrm{mg} / \mathrm{dL} ; \mathrm{p}<0.05)$, and lower triglycerides $(69.8 \pm 25.8 \mathrm{vs} .109 .6 \pm 46.0$ and $132.0 \pm 108.6 \mathrm{mg} / \mathrm{dL} ; \mathrm{p}=0.018)$. The group with
HOMA-IR > p85 presented higher BMI, SBP, WC, total cholesterol and triglycerides. The presence of Acanthosis nigricans was greater in $\mathrm{G}_{\mathrm{p}>95}$. Triglycerides were higher in $\mathrm{G}_{\mathrm{p}>95}$ than in $\mathrm{G}_{\mathrm{p}>85-95}(132.0 \pm 108.6$ vs. 109.6 $\pm 46 \mathrm{mg} / \mathrm{dL} ; \mathrm{p}<0.05)$.

Application of the modified ATPIII criteria to these groups identified Met-S in none of the $\mathrm{G}_{\mathrm{p} 5 \mathrm{p} 25} ; 3.0 \%$ of the $\mathrm{G}_{\mathrm{p} 25-50} ; 9.0 \%$ of the $\mathrm{G}_{\mathrm{p} 50-85} ; 24.4 \%$ of the $\mathrm{G}_{\mathrm{p} 85-95}$ and $26.9 \%$ of the $\mathrm{G}_{\mathrm{p}>95}$. HOMA-IR > 2.1 was significantly associated with Met-S.

$\mathrm{WC}>85^{\text {th }}$ percentile was identified in $9.8 \%, 24.2 \%$, $30.3 \%, 55.5 \%$ and $53.8 \%$; $\mathrm{BP}>90^{\text {th }}$ in $11.3 \%, 12.1 \%$, $15.7 \%, 31.1 \%$ and $30.8 \%$; triglycerides $>90^{\text {th }}$ percentile in $7.0 \%, 18.2 \%, 19.1 \%, 40.0 \%$ and $42.3 \%$; HDL $\leq 40 \mathrm{mg} / \mathrm{dL}$ in $12.7 \%, 18.2 \%, 16.8 \%, 22.2 \%$ and $34.6 \%$, according to HOMA-IR percentiles 5 to 25,25 to 50 , 50 to 85,85 to 95 and $>95$, respectively, as shown in figure 1 .

Table 2. Characteristics of subjects in different HOMA-IR percentiles

\begin{tabular}{|c|c|c|c|c|c|c|}
\hline Percentile & $5-25$ & $25-50$ & $50-85$ & $85-95$ & $>95$ & $\mathbf{p}$ \\
\hline $\mathrm{N}$ & 71 & 66 & 89 & 45 & 26 & \\
\hline HOMA IR & $0.4-0.8$ & $0.81-1.2$ & $1.21-2.0$ & 2.1-2.92 & $>2.93$ & \\
\hline Age (years) & $13.4 \pm 2.6$ & $13.3 \pm 2.4$ & $13.2 \pm 2.5$ & $12.5 \pm 2.0$ & $12.6 \pm 2.1$ & ns \\
\hline Gender (male) & $51(71.8 \%)$ & $26(39.4 \%)$ & $31(34.8 \%)$ & $13(28.9 \%)$ & $8(30.8 \%)$ & * \\
\hline Family history of type 2 diabetes & $45(63.4 \%)$ & $42(63.6 \%)$ & $53(59.6 \%)$ & $30(66.7 \%)$ & $15(57.7 \%)$ & ns \\
\hline $\mathrm{BMI}\left(\mathrm{kg} / \mathrm{m}^{2}\right)$ & $19.6 \pm 3.5$ & $21.1 \pm 3.9$ & $21.6 \pm 5.5$ & $24.7 \pm 5.6$ & $24.8 \pm 7.8$ & $\dagger$ \\
\hline Tanner & $3.5 \pm 1.6$ & $3.8 \pm 1.3$ & $3.7 \pm 1.4$ & $3.7 \pm 1.2$ & $3.8 \pm 1.3$ & ns \\
\hline $\mathrm{SBP}(\mathrm{mmHg})$ & $105.8 \pm 14.9$ & $107.5 \pm 11.4$ & $105.2 \pm 14.8$ & $113.7 \pm 12.4$ & $113.8 \pm 21.2$ & $\ddagger$ \\
\hline $\mathrm{DBP}(\mathrm{mmHg})$ & $65.5 \pm 12.0$ & $64.7 \pm 12.0$ & $63.8 \pm 12.6$ & $68.4 \pm 10.2$ & $68.6 \pm 14.4$ & ns \\
\hline WC (cm) & $68.9 \pm 9.4$ & $72.6 \pm 11.2$ & $75.5 \pm 16.3$ & $84.5 \pm 16.1$ & $83.0 \pm 20.6$ & $\dagger$ \\
\hline Physical activity & $1.5 \pm 1.3$ & $1.1 \pm 1.0$ & $1.1 \pm 1.1$ & $0.9 \pm 0.9$ & $0.9 \pm 0.9$ & $\S$ \\
\hline Birth weight (g) & $3321.7 \pm 689.1$ & $3199.8 \pm 621.2$ & $3166.7 \pm 759.4$ & $3164.0 \pm 655.8$ & $2943.7 \pm 546.0$ & ns \\
\hline Acanthosis nigricans & $6(8.5 \%)$ & $12(18.2 \%)$ & $14(15.7 \%)$ & $7(15.6 \%)$ & $11(42.3 \%)$ & $\bullet$ \\
\hline $\mathrm{TC}(\mathrm{mg} / \mathrm{dl})$ & $160.9 \pm 30.9$ & $163.8 \pm 35.6$ & $154.2 \pm 29.4$ & $171.1 \pm 29.2$ & $157.2 \pm 40.7$ & १ \\
\hline $\mathrm{HDL}(\mathrm{mg} / \mathrm{dl})$ & $53.4 \pm 12.8$ & $48.6 \pm 10.4$ & $49.1 \pm 10.0$ & $47.4 \pm 8.7$ & $46.8 \pm 15.6$ & $\#$ \\
\hline LDL (mg/dl) & $92.7 \pm 24.3$ & $96.3 \pm 30.3$ & $87.8 \pm 23.3$ & $101.9 \pm 23.8$ & $81.1 \pm 18.4$ & ** \\
\hline $\mathrm{TG}(\mathrm{mg} / \mathrm{dl})$ & $69.8 \pm 25.8$ & $92.6 \pm 46.2$ & $86.8 \pm 35.2$ & $109.6 \pm 46.0$ & $132.0 \pm 108.6$ & $\dagger \dagger$ \\
\hline $\mathrm{HbA1c}(\%)$ & $5.3 \pm 0.4$ & $5.3 \pm 0.3$ & $5.2 \pm 0.4$ & $5.3 \pm 0.3$ & $5.2 \pm 0.2$ & ns \\
\hline $\mathrm{FPG}(\mathrm{mg} / \mathrm{dl})$ & $80.1 \pm 10.1$ & $79.8 \pm 8.7$ & $82.7 \pm 10.0$ & $84.2 \pm 10.9$ & $86.4 \pm 10.7$ & $\ddagger$ \\
\hline $2 \mathrm{hPG}(\mathrm{mg} / \mathrm{dl})$ & $78.6 \pm 15.7$ & $85.0 \pm 21.3$ & $86.3 \pm 16.9$ & $92.0 \pm 18.5$ & $89.9 \pm 15.4$ & 护 \\
\hline $\mathrm{FSI}(\mathrm{uU} / \mathrm{ml})$ & $4.3 \pm 1.1$ & $7.4 \pm 0.8$ & $11.4 \pm 1.8$ & $18.0 \pm 1.7$ & $37.4 \pm 26.2$ & $\S \S$ \\
\hline HOMA-B (\%) & $94.7 \pm 29.4$ & $133.1 \pm 38.8$ & $166.7 \pm 50.9$ & $221.6 \pm 74.4$ & $286.1 \pm 90.8$ & $\S \S$ \\
\hline Hcy & $9.6 \pm 2.4$ & $8.7 \pm 2.0$ & $8.9 \pm 1.7$ & $10.2 \pm 2.8$ & $8.6 \pm 1.6$ & 0.091 \\
\hline Met-S & 0 & $2(3.0 \%)$ & $8(9.0 \%)$ & $11(24.4 \%)$ & $7(26.9 \%)$ & $\bullet \bullet$ \\
\hline
\end{tabular}


ROC curve analysis was performed to evaluate the relationship between WC, BMI and HOMA-IR to identify the cluster of cardiometabolic abnormalities among these adolescents. The optimal cutoff point of WC, BMI and HOMA-IR as a predictor of the clus- ter of cardiometabolic abnormalities was $80.5 \mathrm{~cm}$ and $83 \mathrm{~cm}, 20.4$ and $22.7 \mathrm{~kg} / \mathrm{m}^{2}, 1.95$ and 1.65 for males and females, respectively. These data are illustrated in the figure 2 , which shows the differences between the genders.

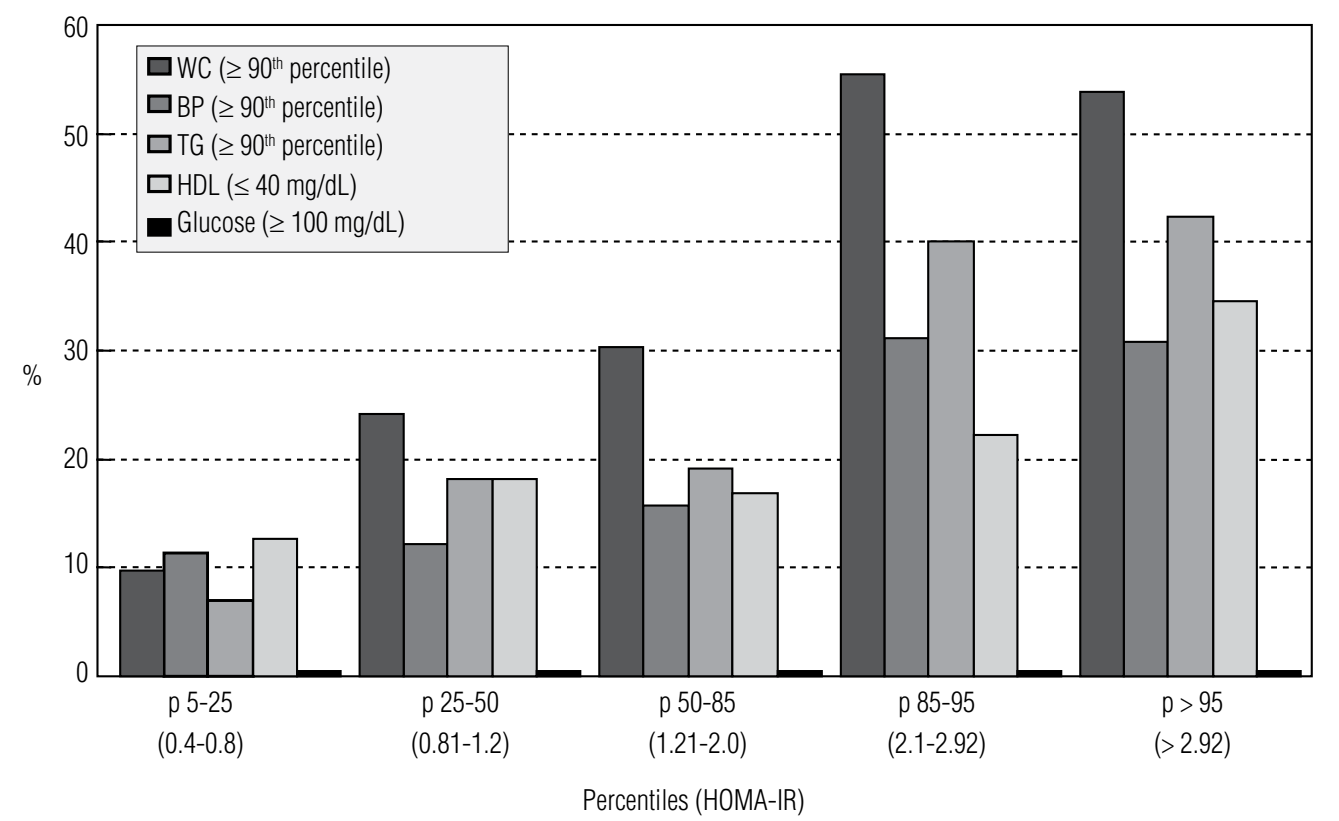

Figure 1. Metabolic syndrome components (ATPIII criteria) identified through the insulin resistance (HOMA-IR) percentiles in the group of adolescents with normal oral glucose tolerance studied.

\section{A}

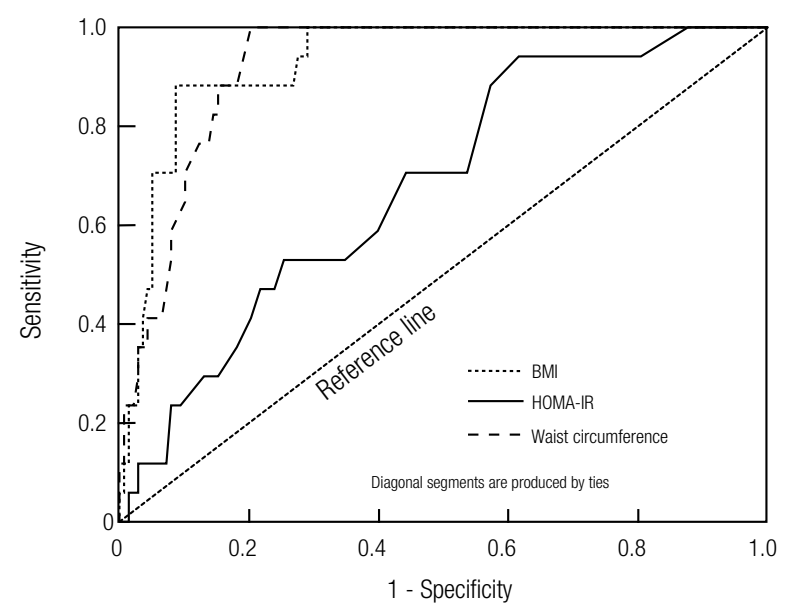

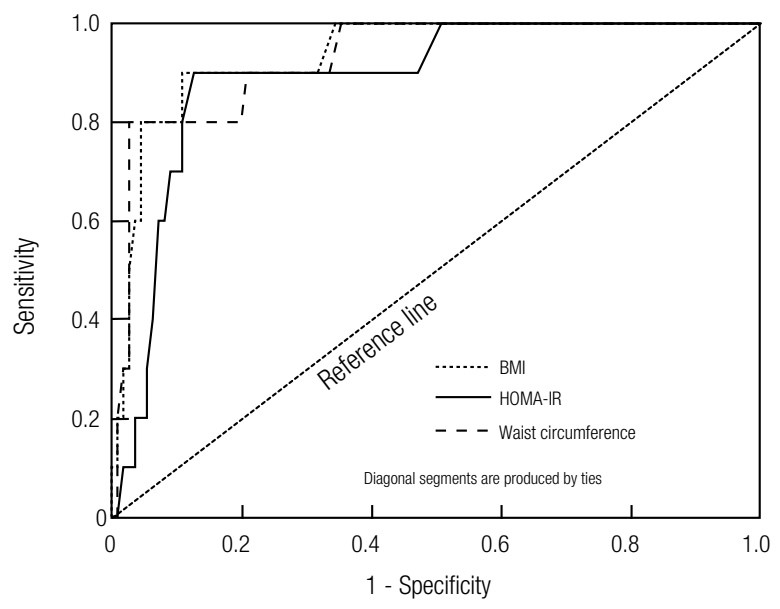

\begin{tabular}{llcccc}
\hline & & Area under curve & Values & Sensitivity & Specificity \\
\hline \multirow{2}{*}{ Waist circumference $(\mathrm{cm})$} & Female & 0.922 & 83.0 & $100 \%$ & $79.7 \%$ \\
& Male & 0.928 & 80.5 & $90 \%$ & $79.1 \%$ \\
\hline \multirow{2}{*}{ BMI $\left(\mathrm{kg} / \mathrm{m}^{2}\right)$} & Female & 0.930 & 22.7 & $100 \%$ & $71.0 \%$ \\
& Male & 0.935 & 20.4 & $100 \%$ & $65.5 \%$ \\
\multirow{2}{*}{ HOMA-IR } & Female & 0.680 & 1.65 & $70.6 \%$ & $55.8 \%$ \\
& Male & 0.890 & 1.95 & $90.0 \%$ & $77.3 \%$ \\
\hline
\end{tabular}

Figure 2. ROC curve analysis and cutoff values for WC, BMI and HOMA-IR to identify normal glucose-tolerant young individuals with a cluster of CVRF in females (A) and males (B). 


\section{DISCUSSION}

The prevalence of Met-S by the age-modified ATPIII criteria was $8.8 \%$ in the whole group of the normal glucose-tolerant Brazilian children and adolescents studied. However, this prevalence was 3 times higher $(25 \%)$ in the specific group of young individuals above the $85^{\text {th }}$ percentile of insulin resistance (HOMA-IR $\geq 2.1$ ).

ROC curve analysis results, showed that BMI and WC values presented high sensitivity (99\% to $100 \%$ ) to detect the cluster of cardiometabolic abnormalities $(\geq 3)$ in both genders of normal glucose-tolerant Brazilian individuals. So did HOMA-IR (90\% sensitivity) in the male subgroup. Among these three measures, WC showed better specificity $(79.7 \%)$ to detect these cardiometabolic signals in these adolescents.

On the whole, our data were similar to the findings from a study on 991 adolescents of similar age range (12-19 years old) from the National Health and Nutrition Examination Study (NHANES) 1999-2000, which used the same criteria for Met-S. In this study, the prevalence of Met-S was $6.4 \%$ (18), but it was higher than in another school-based, cross-sectional study on 1513 black, white and Hispanic teenagers, among whom the prevalence of ATPIII-defined Met-S was 4.2\% (19). This difference on prevalence could be explained by the use of the age-modified ATPIII criteria in our study, and not in the NHANES one.

It is known that the prevalence of Met-S is associated with a degree of overweight, and it has a wide range (6\%-39\%) of prevalence among normal adolescents when different definitions proposed for this condition are considered (20). In our study, Met-S prevalence using the age-modified ATPIII criteria was 1.3\%, 4.2\% and $48.9 \%$ among the normal, overweight and obese individuals, respectively. In a population-based study on Chinese school children, the prevalence rates of Met-S according to the ATPIII definition were $0.9 \%$, $7.6 \%$ and $29.8 \%$ among the normal weight (control group), overweight and obese children, respectively (21). Thus, based on subject's weight, the results related to increased prevalence of Met-S were similar, despite differences in the populations.

Similar to data on adults, WC values could be used to identify children with Met-S, especially considering that references are available in the literature (12). However, there is no consensus, so far, on the method and the value to evaluate this variable in children and adolescents.
Abdominal adiposity was positioned as the sine qua non in the IDF definition of Met-S. Using the new IDF definition for Met-S in children and adolescents, we found a Met-S rate of $5.0 \%$ in our group of individuals, which was lower than the one we found $(8.8 \%)$ with the ATPIII criteria. For normal, overweight and obese subjects, respectively, the comparison between ATPIII and IDF showed 1.3 vs. $0 \%, 4.2$ vs. $2.0 \%$, and 48.9 vs. $31.9 \%$ (data not shown). In the Chinese study, the results were similar and lower than the rates obtained using the ATPIII definition, with $0.1 \%, 5.2 \%$ and $28.6 \%$ in these three groups (21). This lower prevalence in our study can be explained especially by the higher levels of triglycerides used in the ATPIII criteria, compared with the IDF definitions $(150 \mathrm{mg} / \mathrm{dL} v s .110 \mathrm{mg} / \mathrm{dL})$. This was possibly not observed in the Chinese population.

The characteristics of Met-S or related factors among adolescents also showed differences between the genders. In our study, girls presented higher insulin resistance because of higher puberty stage and lower physical activity than boys. However, besides these two factors, the prevalence of Met-S was not higher in girls. Interestingly, fasting plasma glucose $(82.8 \pm 9.4 v s .81 .3 \pm 11.0$ $\mathrm{mg} / \mathrm{dL} ; \mathrm{p}=0.054$ ) showed a tendency to be higher in boys, with lower $\beta$-cell function (HOMA-B: $139.2 \pm$ $75.6 \% v s .178 .0 \pm 72.8 ; \mathrm{p}<0.001)$ than in girls. In spite of the overall lower insulin resistance in boys, they had higher levels of HbAlc (5.4 \pm 0.4 vs. $5.2 \pm 0.3 \%$; p < 0.001 ), albeit within the normal range (22).

The lower pancreatic $\beta$-cell function in boys than in girls may be related to lower insulin resistance and higher Hcy blood levels $(8.8 \pm 2.1$ vs. $9.6 \pm 2.0 \mathrm{mmol} / \mathrm{L}$; $\mathrm{p}=0.010)$ in these individuals. Previous studies have shown that Hcy is higher in boys, and it is independent of the degree of obesity (23). Must and cols. (24) studied 942 boys and 1,085 girls in NHANES III, and showed that sexual dimorphism of Hcy concentrations occurs earlier, at approximately 10 years of age, which is lower than the mean age of our group. We can see in table 1 that Hcy levels did not follow the insulin resistance levels, showing that others factors may have influenced its levels. In vitro studies using clonal BRIN-BD $11 \beta$-cells showed that homocysteine inhibited insulin release in a dose-dependent way at moderate and stimulatory glucose concentrations (25). Thus, we do not know if this levels of homocysteine in boys was influenced in their $\beta$-cell function.

When we analyzed the prevalence of the cluster of cardiometabolic abnormalities at different levels of 
insulin resistance, we saw that CVRF prevalence began to increase significantly after the $85^{\text {th }}$ percentile of HOMAIR (HOMA-IR = 2.1). Above this HOMA-IR value, the prevalence $(24.4 \%)$ of the cluster of cardiometabolic abnormalities in these normal glucose-tolerant young individuals was about 8 times higher than in groups with HOMA-IR below 1.2. It has been demonstrated that the prevalence of the cluster of cardiometabolic abnormalities was positively associated with the degree of HOMA-IR (5). However, current literature does not present any HOMA-IR cutoff point to classify insulin resistance among adolescents. Some studies have shown great variation in mean HOMA-IR levels (1.5-6.3), depending on BMI $(5,26)$, and most of them have used upper tertiles or quartiles to identify insulin resistance. In our overall analysis, HOMA-IR was positively associated with body fat and WC, and it was negatively associated with HDL-C. These data match other findings among adolescents aged 12-19 years (27). Just as in adults, lowered HDL-C also appears to be the metabolic abnormality most associated with insulin resistance in adolescents. In our data the HDL levels were significant lower in the group with HOMA-IR > 2.9 than in the group with HOMA-IR between 0.4-0.8. In the clinical analyses, the prevalence of Acanthosis nigricans was significantly higher only with HOMA-IR $\geq 2$.9.

ROC curve analysis is a way of evaluating the accuracy of a diagnostic test by summarizing the potential of the test to discriminate between the absence and presence of a certain condition. In the context of the present study, this diagnostic accuracy refers to the ability of the anthropometric variables to identify children with the cluster of cardiometabolic abnormalities $(\geq 3)$. From our results, WC appears to have similar effect to that of the BMI in screening for the cluster of cardiometabolic abnormalities. For males, $\mathrm{WC}=80.5 \mathrm{~cm}, \mathrm{BMI}=20.4$ $\mathrm{kg} / \mathrm{m}^{2}$ and HOMA-IR $=1.95$ presented sensitivity of more than $90 \%$, and specificity of more than $65.5 \%$. For females, $\mathrm{WC}=83 \mathrm{~cm}, \mathrm{BMI}=22.7 \mathrm{~kg} / \mathrm{m}^{2}$ and HOMA$-\mathrm{IR}=1.65$ presented sensitivity of more than $70.6 \%$, and specificity of $55.8 \%$. It is important to note that HOMA-IR values ( 1.65 and 1.95 ) that corresponds to the $50^{\text {th }}$ percentile of this population were lower than $50^{\text {th }}$ percentile $($ HOMA-IR $=3.4$ ) of the other Latin (Mexican) children population (23a) and were also associated with increased prevalence of CVRF when compared to the lowest percentile of HOMA-IR values.

Although WC may be useful in estimating visceral fat, the reliability of WC has not been determined yet, especially among children and adolescents. BMI was an excellent parameter in the present study, and was as good as WC for both sexes. Among males, HOMA-IR was as good as WC and BM, but the same was not true for females.

Some limitations of the present study deserve to be acknowledged. First, insulin is not a worldwide standardized assay. Assessment methods differ between laboratories, making comparisons with other studies difficult. Second, the fact that HOMA-IR was used as a surrogate marker for insulin resistance, instead of using the gold standard - hyperinsulinemic euglycemic clamps - could be a possible source of bias. Third, this was a cross-sectional analysis, and therefore causal associations could not be established.

In conclusion, the prevalence of Met-S was $8.8 \%$ in the whole group of normal glucose-tolerant Brazilian children and adolescents, and almost $40 \%$ among overweight subjects. The cluster of cardiometabolic abnormalities that will develop as insulin resistance with time is prevalent and increases significantly above $85^{\text {th }}$ percentile in young individuals. BMI and WC were good predictors for the cluster of cardiometabolic abnormalities among children. The construction of ROC curves enables the identification of the best cutoff point at which these variables are best indicators of the cardiovascular risk cluster.

One particular aspect to point out in relation to other similar studies from US and Europe is the absence of type 2 diabetes in the group of high cardiovascular risk Brazilian adolescents, so far. This absence may be related to the degree of obesity or to $\beta$-cell function. A recent study has shown that this is one of the principal factors differentiating between normal glucose tolerance, impaired glucose tolerance, and type 2 diabetes (28) in this age group. Therefore, our data point out the heterogeneity of the relationship between the degree of insulin resistance in children and adolescents and cardiometabolic abnormalities in different populations.

Nonetheless, data from the present study shows that practice (BMI and WC) and laboratory-based (HOMA-IR) information, and their respective cutoff points may be applied to detect a cluster of cardiometabolic abnormalities in children and adolescents. Timely diagnosis is important for appropriated prevention and treatment of these strong markers in order to reduce the associated risk of metabolic and cardiovascular disease in young populations. 
Disclosure: no potential conflict of interest relevant to this article was reported.

\section{REFERENCES}

1. Ebbeling CB, Pawlak DB, Ludwig DS. Childhood obesity: public-health crisis, common sense cure. Lancet. 2002;360:473-82.

2. Daniels SR, Jacobson MS, McCrindle BW, Eckel RH, Sanner BM. American Heart Association childhood obesity research summit: executive summary. Circulation. 2009;119:2114-23.

3. Veiga GV, Cunha AS, Sichieri R. Trends in overweight among adolescents living in the poorest and richest regions of Brazil. Am J Public Health. 2004;94(9):1544-8.

4. Kashyap SR, Defronzo RA. The insulin resistance syndrome: physiological considerations. Diab Vasc Dis Res. 2007;4(1):13-9.

5. Silva RCQ, Miranda WL, Chacra AR, Dib SA. Metabolic syndrome and insulin resistance in normal glucose tolerant Brazilian adolescents with family history of type 2 diabetes. Diabetes Care. 2005;28(3):716-8.

6. Banerji MA, Faridi N, Atluli R, Chaiken RL, Lebovitz HE. Body composition, visceral fat, leptin, and insulin resistance in Asian Indian men. J Clin Endocrinol Metab. 1999;84:137-44.

7. Di lorgi N, Mittelman SD, Gilsanz V. Differential effect of marrow adiposity and visceral and subcutaneous fat on cardiovascular risk in young, healthy adults. Int J Obes (Lond). 2008;32:1854-60.

8. Gutin B, Johnson MH, Humphries MC, Hatfield-Laube JL, Kapuku GK, Allison JD, et al. Relationship of visceral adiposity to cardiovascular disease risk factors in black and white teens. Obesity. 2007;15:1029-35.

9. Levy-Marchal C, Arslain S, Cutfield W, Sinaiko A, Druet C, Marcovecchio $M L$, et al. Insulin resistance in children: consensus, perspective, and future directions. J Clin Endocr Metab. 2010;95(12):5189-98.

10. Tanner JM. Growth and maturation during adolescence. Nutr Rev. 1981;39:43-55.

11. Centers for Disease Control and Prevention 1600 Clifton Rd. Atlanta, GA 30333, USA. Available at: http://www.cdc.gov/nchs/ data//nhanes/growthcharts/statage.txt. and http://www.cdc.gov/ nchs/data/nhanes/growthcharts/wtage.txt. Acessed: April 2008.

12. Moreno LA, Pineda I, Rodríguez G, Fleta J, Sarria A, Bueno M. Waist circumference for the screening of metabolic syndrome in children. Acta Paediatr. 2002;91:1307-12.

13. Hypertension Brazilian Society, Brazilian Society of Cardiology \& Brazilian Society of Nephrology. IV Brazilian guidelines to arterial hypertension. São Paulo, SP, Brazil, 2002.

14. Marshall A, Baumann A. The international physical activity questionnaire summary report of the reliability and validity studies. Document of IPAQ Executive Committee, World Health Organization, 2001.
15. American Diabetes Association. Standards of Medical Care in Diabetes-2009. Diabetes Care. 2009;32:S13-S61.

16. WallaceTM, Levy JC, Matthews DR. Use and abuse of HOMA Modeling. Diabetes Care. 2004;27(6):1487-95.

17. Executive Summary of the Third Report of the National Cholesterol Education Program (NCEP) Expert Panel on Detection, Evaluation, and High Blood Cholesterol in adults (Adult Treatment Panel III). JAMA. 2001;285:2486-97.

18. Duncan GE, Sierra ML, Zhou X-H. Prevalence and trends of a metabolic syndrome phenotype among U.S. adolescents. Diabetes Care. 2004;27:2438-43.

19. Goodman E, Daniels SR, Morrison JA, Huang B, Dolan LM. Contrasting prevalence of and demographic disparities in the World Health Organization and National Cholesterol Education Program Adult Treatment Pannel III definitions of metabolic syndrome. J Pediatr. 2004;145:445-51.

20. Reinehr T, Sousa G, Toschke AM, Andler W. Comparison of metabolic syndrome prevalence using eight different definitions: a critical approach. Arch Dis Child. 2007;92(12):1053-4.

21. Wan NJ, Wang TY, Duan JL, Li M, Gong CX, Du JB, et al. Metabolic syndrome in overweight and obese schoolchildren in Beijing (Abstract). Zhonghua er Ke ZA Zhi. 2007;45(6):417-21.

22. Fonseca $V$, Inzucchi SE, Ferrannini E. Redefining the diagnosis of diabetes using glycated hemoglobin. Diabetes Care. 2009;32(7):1344-5.

23. Brasileiro RS, Escrivão MA, Taddei JA, D'Almeida V, Ancona-Lopez F, Carvalaes JT. Plasma total homocysteine in Brazilian over weight and non overweight adolescents: a case control study. Nutr Hosp. 2005;20(5):313-9.

24. Must A, Jacques PF, Rogers G, Rosenberg IH, Selhub J. Serum total homocysteine concentrations in children and adolescents: results from the third National Health and Nutrition Examination Survey (NHANES III). J Nutr. 2003;133(8):2643-9.

25. Patterson S, Flatt PR, Brennan L, Newsholme P, McClenaghan NH. Detrimental actions of metabolic syndrome risk factor, homocysteine, on pancreatic Beta-cell glucose metabolism and insulin secretion. J Endocr. 2006:189:301-10.

26. Alvarez MM, Vieira ACR, Moura AS, Veiga GV. Insulin resistance in Brazilian adolescent girls: association with overweight and metabolic disorders. Diabetes Res Clin Pract. 2006;74:183-8.

27. Juárez-López $C$, Klünder-Klünder $M$, Medina-Bravo $P$, Madrigal-Azcárate A1, Eliezer Mass-Díaz E, Flores-Huerta S. Insulin resistance and its association with the components of the metabolic syndrome among obese children and adolescents. BMC Public Health. 2010;10:318.

28. Bacha F, Gungor N, Lee SJ, Arslanian SA. In vivo insulin sensitivity and secretion in obese youth: what are the differences between normal glucose tolerance, impaired glucose tolerance, and type 2 diabetes? Diabetes Care. 2009;32:100-5. 